\title{
IDENTIFICACIÓN DE LeguminOSAE-CAesalpinioideAe ARBUSTIVAS- arbóreas y lianas de la SElVa Paranaense (Misiones, ARgENTINA) UTILIZANDO CARACTERES VEgETATIVOS
}

\author{
MARCELO R. KOSTLIN¹ \\ "...Uno piensa que los días de un árbol son todos iguales. Sobre todo si es un árbol viejo. \\ No. Un día de un viejo árbol es un día del mundo..." \\ (Fragmento de "La balada del álamo Carolina" de Haroldo Conti)
}

\begin{abstract}
Summary: Identification of woody Leguminosae-Caesalpinioideae of Paranaense forest (Misiones, Argentina) using vegetative characters. In this study, I explored the diversity of vegetative morphological traits of native taxa of Leguminosae-Caesalpinioideae (in the traditional circumscription) from Misiones Province of Argentina, in order to facilitate the identification of genera, species, subspecies, and varieties in the absence of flowers and fruits. Herbarium specimens from the 15 species of shrubs - trees and lianas of Caesalpinioideae belonging to 10 genera present in Misiones were studied. The analyzed traits were: life form, phyllotaxis, stem, leaf, stipules, glands and extrafloral nectaries, type of venation, pubescence, and buds. As a result, an identification key to all taxa studied and descriptions of vegetative characters of all the taxa are presented. A discussion of the diversity observed in vegetative characters is also added, as well as observations about distribution, habitat, and phenology. In addition, a vegetative key to subfamilies of shrubs-trees and lianas of Leguminosae of the Paranaense forests of Misiones is provided to facilitate identification of the Caesalpinioideae. In summary, these keys will be crucial for an accurate identification of Caesalpinioideae subfamily and their species, in seasons when flowers and fruits are absent.
\end{abstract}

Key words: Distribution, habitat, herbarium specimen, identification key, morphology, native taxa, phenology.

Resumen: En este trabajo se estudia la diversidad de caracteres morfológicos vegetativos de taxones nativos de la familia Leguminosae-Caesalpinioideae (en su sentido tradicional) de la Provincia de Misiones, Argentina, a fin de facilitar la identificación de géneros, especies, subespecies y variedades en ausencia de sus flores y frutos. Se estudiaron ejemplares de herbario de las 15 especies, subespecies y variedades de Caesalpinioideae arbustivas-arbóreas y lianas pertenecientes a 10 géneros presentes en Misiones. Los caracteres analizados fueron hábito, filotaxis, tallo, hojas, estípulas, glándulas y nectarios extraflorales, tipo de venación, pubescencia y yemas. Como resultado se presenta una clave para la identificación de todos los taxones estudiados y descripciones de sus caracteres vegetativos. A su vez se discute la variabilidad observada en los caracteres vegetativos, así como observaciones sobre distribución, hábitat y fenología. Además, se proporciona una clave vegetativa de subfamilias de Leguminosae arbustivas-arbóreas y lianas presentes en la selva Paranaense de Misiones para facilitar la identificación de las Caesalpinioideae. En resumen, estas claves serán cruciales para una identificación precisa de la subfamilia de Caesalpinioideae y sus especies, en las estaciones en que sus flores y frutos están ausentes.

Palabras clave: Clave de identificación, distribución, especies nativas, fenología, hábitat, herbario, morfología.

${ }^{1}$ Instituto de Investigación en Biodiversidad y Medioambiente (INIBIOMA), CONICET-UNComahue. Quintral 1250 -S. C. de Bariloche, Rio Negro, Argentina. C.P. 8400, marcekos@yahoo.com 


\section{INTRODUCCIÓN}

Habitualmente cuando se realizan descripciones botánicas de taxones, los caracteres vegetativos suelen tener menor relevancia y estar descriptos con menor detalle que los caracteres reproductivos. Esto se debe a que los primeros suelen considerarse más variables y sujetos a variaciones ambientales, y menos indicativos de relaciones de parentesco entre grupos (Hickey \& Wolfe, 1975). Por otra parte, muchas veces existe la dificultad de acceder a los órganos reproductivos de las plantas cuando se trabaja a campo, ya sea por su ausencia en el momento de estar en el terreno (por no encontrarse en floración) o porque el mismo se encuentra en estadios ontogenéticos pre-adultos, quedando sólo a disposición los órganos vegetativos. De modo que el uso de los caracteres vegetativos para la identificación de taxones podría conferir la ventaja de encontrarse en forma persistente durante períodos de tiempo prolongados, haciendo que sean observables con mayor facilidad, y pudiendo ser utilizados en ausencia de sus flores o frutos (Keller, 1996a).

Los trabajos para la identificación de taxones basados en caracteres vegetativos han aumentado desde la década del 70 (e. g. Mantovani et al., 1985; García Murillo, 1991; Gentry, 1996; Keller, 1996a; Urbanetz et al., 2010), debido a su gran utilidad a la hora de realizar inventarios florísticos a campo, estudios ecológicos de monitoreo permanente, o reconocimiento de individuos en estadio de plántula (Silva et al., 1988; Marino et al., 2008; Puntieri \& Chiapella, 2011). En ecosistemas tropicales y subtropicales la alta diversidad florística unida a la poca variación climática estacional genera una gran diversidad de patrones fenológicos complejos de floración (Newstrom et al., 1994). Esto, sumado al difícil acceso a las estructuras reproductivas en los diferentes estratos del dosel (Urbanetz et al., 2010), dificultan la identificación de las especies (Keller, 1996a; Ash et al., 1999). Las ventajas de la utilización de caracteres vegetativos en claves de reconocimiento de plantas leñosas de América tropical y subtropical han sido planteadas por varios autores (Mantovani et al., 1985; Gentry, 1996; Keller, 1996a, 1996b;
Miranda et al. 2000; Bohren et al. 2003; Braz et al. 2004; Hargreaves, 2006; Sobral et al., 2006; Urbanetz et al., 2010), justificando la necesidad de su uso para la identificación de taxones, muchos de los cuales se encuentran revisionados por Rejmanek \& Brewer (2001).

Según Weberling (2006), varios caracteres vegetativos foliares, como por ejemplo las estípulas, son órganos característicos y constantes a nivel taxonómico, los cuales ocurren en un gran número de familias. Así, la presencia y la variabilidad interespecífica en la morfología de las estípulas resultan relevantes para la identificación de especies o variedades de plantas. De esta forma, el aporte y compendio de información de los caracteres vegetativos foliares de taxones leñosos de ambientes tropicales, podría ser una herramienta fundamental para su identificación a campo.

En la familia de las leguminosas, los caracteres vegetativos foliares cumplen un papel taxonómico importante, ya que su diversidad, persistencia y poca variabilidad intra-específica permite la identificación de taxones (Keller, 1996b).

La filogenia de esta gran familia ha sido objeto de estudio durante mucho tiempo, sobre todo en la subfamilia Caesalpinioideae, un grupo problemático por no ser monofilético (Irwin, 1981). Un estudio reciente plantea una nueva clasificación de la familia en 6 subfamilias monofiléticas para darle solución a este problema (LPWG, 2017). Sin embargo, en este trabajo utilizaremos el criterio en sentido tradicional de Lewis et al., (2005) donde la Familia Leguminosae o Fabaceae, se clasifica en tres subfamilias: Mimosoideae, Caesalpinioideae y Faboideae o Papilionoideae. Estas tres subfamilias se encuentran muy diversificadas en el Neotrópico, en particular la subfamilia Caesalpinioideae, la cual cuenta con 65 géneros y aproximadamente 1200 especies en Sudamérica, siendo los géneros más representados Senna Mill. (ca. 146 especies) y Bauhinia L. (75 especies) (Ulibarri, 2008). Un listado de géneros para las tres subfamilias, coloca a las Caesalpinioideae como la segunda subfamilia más importante en Sudamérica en términos forestales, después de las Papilionoideae (Burkart, 1952). 
Las especies de esta subfamilia que habitan en la Provincia de Misiones (Argentina) crecen en bosques donde predomina la vegetación de selva subtropical semi-decidua. Esta región con gran diversidad florística posee el $30 \%$ del total de las especies que existen en la Argentina (Zuloaga et al., 1999) y es denominada según el autor como "Selva Paranaense" (Cabrera, 1976; Cabrera \& Willink, 1980), "Bosque Atlántico Interior del Alto Paraná" (Di Bitetti et al. 2003) o "Selva Atlántica interior" (Giraudo \& Povedano, 2004). La misma se encuentra subdividida en dos grandes distritos fitogeográficos, hacia el norte el de las selvas mixtas y hacia el sur el de los campos y sabanas (Cabrera, 1976).

Las Caesalpinioideae en esta área están representadas por taxones que poseen todo tipo de hábitos, encontrándose en variados ambientes dentro de este ecosistema. Desde especies de habito arbóreo asociadas fundamentalmente a las selvas en galería sobre cursos de agua (e. g. Gleditsia amorphoides (Griseb.) Taub., Bauhinia affinis Vogel, Bauhinia uruguayensis Benth., Cynometra bauhiniifolia Benth. y Copaifera langsdorffii (Desf.) (Marchiori, 1997; Fortunato, 1996, 1997; Ulibarri, 1997b, Vanni et al., 2003), pasando por especies de habito arbóreo de gran porte creciendo fundamentalmente en selvas y montes como Peltophorum dubium (Spreng.) Taub., Pterogyne nitens Tul., Apuleia leiocarpa (Vogel) J.F. Macbr., (Ulibarri, 1997c). A su vez se pueden encontrar especies asociadas a las comunidades de las selvas de Araucaria angustifolia (Bertol.) Kuntze pudiendo encontrarse específicamente arbustos de Senna oblongifolia (Vogel) H.S. Irwin \& Barneby (Schütz Rodrigues et al. 2005). En comunidades de sucesión secundaria (e. g. bordes de caminos) son muy frecuentes especies de arbustos y arbolitos heliófitos de Senna pendula (Humb. \& Bonpl. ex Willd.) H.S. Irwin \& Barneby, Senna corymbosa (Lam.) H.S. Irwin \& Barneby y Bauhinia forficata subsp. pruinosa (Vogel) Fortunato \& Wunderlin (Schütz Rodrigues et al. 2005, Bernardi, 1984). Finalmente se pueden encontrar especies arbustivas circunscriptas exclusivamente al distrito de los campos como Pomaria rubicunda (Vogel) B.B. Simpson \& G.P. Lewis (Ulibarri, 1997a).

La descripción e identificación en forma vegetativa de los taxones de esta interesante subfamilia de gran importancia forestal, podría aportar a las determinaciones a campo en esta área de estudio y en localidades aledañas que involucren a la selva paranaense de Brasil y Paraguay (Urbanetz et al., 2010).

El objetivo general del presente trabajo fue contribuir a la diferenciación de taxones de Caesalpinioideae (Leguminosae) arbustivasarbóreas y lianas nativas de la selva Paranaense de la provincia de Misiones (Argentina) en ausencia de flores y frutos. Específicamente se propuso: a) elaborar una clave dicotómica para la identificación de taxones de esta subfamilia, de gran importancia forestal, utilizando caracteres vegetativos $\mathrm{y}, \mathrm{b})$ proveer de descripciones detalladas de los caracteres vegetativos caulinares $\mathrm{y}$ foliares de todos los taxones incluidos en ella mediante observación de material de herbario.

\section{Materiales y Métodos}

A partir del "Catálogo de las plantas vasculares del Cono Sur” (Zuloaga et al. 2008) se listaron todos los taxones arbustivos-arbóreos y lianas nativos pertenecientes a la Subfamilia Caesalpinioideae sensu Lewis et al. (2005) presentes en la Provincia de Misiones para ser analizados mediante material de herbario.

El listado arrojó un total de 10 géneros, 15 especies, 1 subespecie y 6 variedades de taxones de Leguminosae-Caesalpinioideae arbustivos, arbóreos y lianas nativas para la Provincia de Misiones. Este listado tuvo en cuenta a las especies nativas excluyendo a las especies naturalizas presentes allí.

Los tipos de hábitos tomados en cuenta en este estudio fueron: arbusto, arbusto-arbolito, arbolito, árbol, liana, definidos por el "Catálogo de las plantas vasculares del Cono Sur" (Zuloaga et al. 2008). Los taxones de hábito subarbustivos y sufrútices presentes en la Provincia de Misiones fueron excluidos del análisis (en particular en Caesalpinioideae el género Chamaecrista Moench y algunas especies del género Senna spp. que poseen estos hábitos).

Las observaciones en los taxones tratados se realizaron sobre ejemplares de herbario fértiles (entre 2 a 8 ejemplares por taxón) a los 
efectos de contar con una identificación precisa. Los mismos contabilizaron una totalidad de 64 ejemplares de herbario, depositados en el Herbario del Instituto de Botánica Darwinion (SI). Cuando no se encontraron ejemplares del área bajo estudio se utilizaron ejemplares de áreas limítrofes de Paraguay, Brasil, y/o de la provincia de Corrientes (Argentina), eligiendo localidades afines en términos ambientales. Se observó el material a ojo desnudo y bajo lupa binocular con aumentos de entre 6x y 50x. Las dimensiones de todas las estructuras morfológicas fueron medidas con regla milimetrada y expresadas en centímetros. En cuanto a la medición de las hojas, se seleccionaron las que se encontraban completas buscando que sean representativas del ejemplar analizado. En el caso de las hojas compuestas, se seleccionaron hojas que posean todos sus folíolos para medirlos en su totalidad con el objetivo de conseguir los valores mínimos y máximos de cada ejemplar. Todas las mediciones fueron contrastadas con descripciones de la bibliografía.

Los caracteres vegetativos observados a nivel foliar tuvieron en cuenta: tipo de hoja (compuesta o simple), filotaxis de hoja y folíolos, tipo de yema, morfología del raquis principal, presencia de estructuras secretoras (e. g. nectarios extraflorales, glándulas, puntos translúcidos inmersos en la lámina), y caracteres encontrados en la lámina (ápice, borde, superficie, tipo de nerviación). A nivel caulinar se tuvo en cuenta la forma, pubescencia y corteza de las ramas, la disposición de yemas, y la presencia de zarcillos ${ }^{2}$, acúleos $^{3}$ y espinas ${ }^{4}$. Se realizaron descripciones de estas características morfológicas, ilustraciones esquemáticas y fotografías de las estructuras diagnósticas. Se complementó la información de los taxones con datos fenológicos de floración y fructificación, fenología foliar, y tipo de ambiente donde habitan, generalmente

2 Órgano filamentoso de origen caulinar o foliar especializado con función trepadora para sujetarse a una superficie o a otras plantas (Font Quer, 1985).

3 Aguijón o púa generalmente caedizo que se origina en el tejido dérmico de algunas plantas y carece de tejido vascular (Font Quer, 1985).

4 Formaciones agudas, aleznadas, rígidas, a veces ramificadas, provistas de tejido vascular, muy ricas en tejidos de sostén, de origen caulinar o foliar (Font Quer, 1985). obtenida de bibliografía. Con esta información se elaboró una clave de reconocimiento de especies arbustivas-arbóreas y lianas de Caesalpinioideae utilizando caracteres vegetativos a nivel de rama y hoja, buscando caracteres mutuamente excluyentes (Miranda et al., 2000). Los términos utilizados en la confección de las claves y las descripciones botánicas siguieron los conceptos de Hickey (1979) para la morfología y tipo de venación de la lámina foliar, de Martínez (1975) para el tipo de yema, y de Font Quer (1985) para el resto de la terminología. Previo a la clave para diferenciar estos taxones mediante caracteres vegetativos y a sus respectivas descripciones, se incluye una clave para la identificación de plantas de las subfamilias de Leguminosae sensu Lewis et al. (2005) a través de caracteres vegetativos foliares, realizada a partir de Keller (1996a), Ribeiro et al. (1999) y Queiroz (2009). Esta clave es necesaria para verificar que el material a identificar pertenezca efectivamente a la subfamilia Caesalpinioideae.

\section{Resultados}

A partir de características exclusivamente vegetativas pudieron diferenciarse todos los taxones de Leguminosae-Caesalpinioideae arbustivos-arbóreos y lianas nativas para la Provincia de Misiones.

Las Leguminosae leñosas de Misiones se pueden identificar por un síndrome de caracteres vegetativos foliares que se listan a continuación: hojas de filotaxis alterna, láminas compuestas (pinnadas a bipinnadas) o simples bilobadas, de margen entero a crenado, con venación pinnada, venación secundaria broquidódroma, pecíolos pulvinados y peciólulos pulvinulados ${ }^{5}$, y presencia de estípulas de morfología variada (Hickey \& Wolfe 1975, Cowan, 1981, Gentry, 1996, Keller, 1996a, Ribeiro et al., 1999 y Sobral et al., 2006).

5 Dilataciones formadas por una estructura cilíndrica de tejido diferenciado, en base o ápice del pecíolo o pecíolulo, los cuales presentan una zona de abscisión nítida que los separa de la rama y del raquis respectivamente (Ribeiro et al., 1999). 


\section{Clave para la identificación de subfamilias de Leguminosae arbustivas- arbóreas y lianas nativas de la provincia de Misiones (Argentina)}

1. Hojas bipinnadas. 2

1a. Hojas pinnadas o simples bilobadas. 4

2(1). Hojas con nectarios extraflorales. MIMOSOIDEAE (Acacia spp., Albizia spp., Chloroleucon tenuiflorum (Benth.) Barneby \& J.W. Grimes, Zygia spp., Mimosa spp., Enterolobium contortisiliquum (Vell.) Morong, Parapiptadenia rigida (Benth.) Brenan, Anadenanthera colubrina (Vell.) Brenan)

2a. Hojas sin nectarios extraflorales. 3

3(2). Hojas imparibipinnadas.

MIMOSOIDEAE (Calliandra spp., Zapoteca portoricensis (Jacq.) H.M. Hern. ssp. flavida (Urb.) H.M. Hern.)

3a. Hojas paribipinnadas.

CAESALPINIOIDEAE

(Ver clave de especies tratadas)

4(1). Hojas simples bilobadas.

CAESALPINIOIDEAE

(Ver clave de especies tratadas)

4a. Hojas pinnadas. 5

5(4). Hojas imparipinnadas, trifolioladas o unifolioladas (exceptuando paripinnadas en Sesbania spp.). Nunca bipinnadas. Folíolos estipelados. Raquis o pecíolo sin glándulas o nectarios extraflorales.

PAPILIONOIDEAE

(Acosmium subelegans (Mohlenbr.) Yakovlev, Ateleia glazioveana Baill., Dalbergia frutescens (Vell.) Britton, Dahlstedtia pinnata (Benth.) Malme, Poecilanthe parviflora Benth., Lonchocarpus sp., Holocalyx balansae Micheli, Machaerium sp., Myrocarpus frondosus Allemão, Cyclolobium brasiliense Benth., Canavalia spp., Camptosema spp.)

5a. Hojas bifolioladas, paripinnadas, o pseudo imparipinnadas (exceptuando imparipinnada en Apuleia leiocarpa (Vogel) J.F. Macbr.). Folíolos no estipelados. Pecíolo o raquis frecuentemente con glándulas. 6

6(5). Hojas con raquis alado, nectario extrafloral glanduloso sésil, en platillo, en cada yugo.

MIMOSOIDEAE

(Inga spp.)

6a. Hojas sin raquis alado, nectarios extraflorales glandulosos de forma diferente a como en anterior, o sin nectarios.

CAESALPINIOIDEAE

(Ver clave de especies tratadas)

\section{Clave de identificación de las especies leñosas de Leguminosae-Caesalpinioideae de Misiones}

1. Hojas simples con lámina lobada. 2

1a. Hojas compuestas. 5

2(1). Lianas o arbustos escandentes con zarcillos intra-estipulares. Bauhinia microstachya

2a. Árboles o arbustos, sin zarcillos. 3

3(2). Sin acúleos, generalmente con espinas en las ramas. Ramas totalmente glabras con lenticelas circulares conspicuas. Bauhinia uruguayensis

3a. Con acúleos, sin espinas en ramas. Ramas pubescentes a glabras sin lenticelas conspicuas en las ramas. 4 4(3). Acúleos dimórficos, subgeminados, el mayor infraestipular, conoidal, incurvo o recto-ascendente; el menor estipular, unguiculado. Bauhinia affinis 


\section{Bol. Soc. Argent. Bot. 52 (3) 2017}

4a. Acúleos homomórficos, geminados infraestipulares, cónicos, recurvos a incurvos.

Bauhinia forficata subsp. pruinosa

5(1). Árboles. Nunca arbustos. 6

5a. Arbustos o arbolitos, nunca árboles. ............................................................................................. 14

6(5). Folíolos 1-15 pares. Hojas pinnadas y a veces bipinnadas en la misma planta en ramas adultas. ........ 7

6a. Folíolos 6-30 pares. Hojas siempre bipinnadas a veces pinnadas en la misma planta. ........................ 13

7(6). Folíolos crenados. Presencia de yemas múltiples seriales. Plantas a veces con espinas.

Gleditsia amorphoides

7a. Folíolos no crenados. Ausencia de yemas múltiples seriales. Plantas siempre inermes. ....................... 8

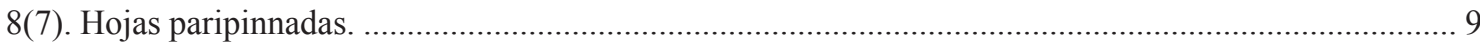

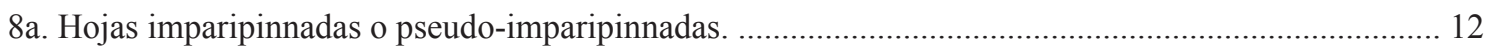

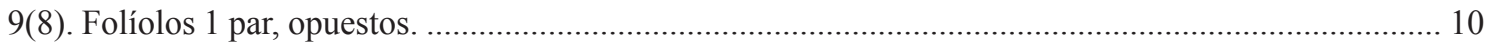

9a. Folíolos 2-numerosos, alternos a subopuestos. ................................................................................... 11

10(9). Folíolos con margen revoluto, y sin nervio marginal continuo, 1-4 x 0,5-2 cm. Envés puberulento. ..

Cynometra bauhiniifolia var. meridiana

10a. Folíolos sin margen revoluto, con nervio marginal continuo, 4,8-7,8 x 2,7-4,1 cm. Envés densamente pubescente.

Hymenaea martiana

11(9). Folíolos anchamente elípticos, ápice no atenuado, subcoriáceos, sin glándulas y nectarios extraflorales. Margen subrevoluto. Pterogyne nitens

11a. Folíolos ovado-elípticos de ápice atenuado, coriáceos, con glándula sésil en el margen basal-externo de cada folíolo y otras translúcidas en la lámina. Margen no revoluto.

Copaifera langsdorffi var. langsdorffii

12(8). Hojas pseudo-imparipinnadas. Raquis anchamente surcado en el dorso, pecíolulos breves, glabros, folíolos anchamente elípticos, ápice retuso, obtuso, (4-)7-8 pares. Pterogyne nitens

12a. Hojas imparipinnadas. Raquis sin surco dorsal, pecíolulos alargados, muy pilosos, folíolos, ovadoelípticos, apiculados, ápice subagudo, (3-)5-11 pares. Apuleia leiocarpa

13(6). Folíolos crenados, 10-40 x 4-7 mm de margen no revoluto. Yemas múltiples. Plantas a veces con espinas.

Gleditsia amorphoides

13a. Folíolos no crenados de margen revoluto, 5-14 x 2,5-5 mm. Yemas simples. Plantas siempre inermes. Peltophorum dubium

14(5). Ramas no fistulosas, con exfoliación longitudinal en finas laminillas papiráceas. Hojas imparibipinnadas, sin glándulas peciolares o raqueales; folíolos subsésiles, con puntuaciones glandulosas incrustadas en la lámina.

14a. Ramas generalmente fistulosas, sin exfoliación como en 14. Hojas paripinnadas con nectarios extraflorales glandulosos peciolares o raqueales; folíolos peciolulados, sin puntuaciones glandulosas en la lámina.

15(14). Folíolos elípticos-ovado, subagudos, menos de $0,5 \mathrm{~cm}$ long., con numerosas puntuaciones glandulosas incrustadas en el envés. Estípulas subuladas, enteras. .... Pomaria rubicunda var. rubicunda

15a. Folíolos deltoides-subcordiformes, agudos, mayores de 0,5 cm long., con escasas puntuaciones en el envés. Estípulas lineares, enteras o a veces con 1-2 divisiones laterales. .. Pomaria rubicunda var. hauthalii

16 (14). Ramas pubérulas. Nectario extrafloral glanduloso en zona media del pecíolo. Folíolos 4-8 (-10) pares, largamente subovovada a anchamente elípticos, base obtusa, ápice retuso, apiculado, conspicuamente discoloros.

Senna oblongifolia

16a. Ramas glabras. Nectario extrafloral glanduloso en el primer par de folíolos. Folíolos 2-4 (-6) pares, 
largamente ovados a anchamente o angostamente elípticos, agudos a obtusos; apículo inconspícuo o ausente, concoloros a levemente discoloros.

17(16). Folíolos 2-3 (4), largamente ovados con ápice agudo a subagudo, no emarginados, 2-6 x 0,4-1,2 cm.

Senna corymbosa

17a. Folíolos (3-) 4-6, anchamente elíptico, con ápice obtuso, emarginado, 1,5-4,3 x 0,8-1,6 cm.

Senna pendula

Descripción de taxones leñosos de Caesalpinioideae de Misiones (Argentina)

Subfamilia Caesalpinioideae (DC.) K. R. Robertson \& Y. T. Lee, J. Arnold Arbor 57 (1): 1. 1976. Subord. Caesalpinea De Candolle, Prodr. 2: 473. 1825. Ord. Caesalpineae Brown, Voy. Terra austral. 2: 19. 1814; reprinted in Misc. Bot. Works. 1:23. 1866.

Árboles, a veces con raíces tabulares, arbustos, o hierbas, anuales o perennes, menos frecuentemente lianas, inermes o no, con o sin indumento de tricomas simples o glandulares variados. Nectarios extraflorales presentes en pecíolos y raquis de hojas en diversos géneros. Hojas alternas, pecioladas, bipinnadas o pinnadas, menos frecuentes simples o reducidas, margen de la lámina entero, estípulas pequeñas, deltoides, subuladas, filiformes a foliáceas, pinnadas, a veces espinescentes, persistentes o caducas; folíolos escasos a numerosos, generalmente opuestos a subopuestos.

Apuleia leiocarpa (Vog.) J. F. Macbr., Contr. Gray Herb. 59: 23. 1919

\section{Iconografia. Sousa et al. (2010: 230, Fig. 3).}

Árboles caducifolios, inermes, 6-20 (30) m alt. Filotaxis alterna espiralada. Estípulas oblanceoladas caedizas. Hojas imparipinnadas; folíolos 5-11 por pinna, alternos, elípticos, obtusos o agudos, apiculados, 2-5 (6) x 0,7-1,8 (2) cm, el terminal más grande que los otros, subcoriáceos o coriáceos, levemente discoloros, cara abaxial con pubescencia adpresa, densa, breve; peciólulos conspicuos, pubérulos, retorcidos (Ver Figura 1).

Nombres vernáculos. Grapia, Yvyrá-peré.
Distribución y hábitat. Crece en selvas y márgenes de ríos, entre los $150-700 \mathrm{~m} \mathrm{~s}$. n. m., en las en la Prov. Biogeográfica Amazónica y Paranaense: Paraguay, sudeste de Brasil y extremo nordeste de Argentina (Misiones y Corrientes) (Ulibarri, 1997c).

Observaciones. Florece de septiembre a octubre y fructifica desde febrero a octubre (Pereira et al., 2008). Se caracteriza por el follaje verde claro deciduo. La floración precede muy poco a la aparición de las nuevas hojas (Bernardi, 1984), y la corteza posee exfoliación en placas redondeadas irregulares pardo cenicientas. Los ejemplares citados varían de 15-20 m alt.

Material examinado. ARGENTINA. Prov. Misiones. Depto. Iguazú, Salto Iguazú. 2552’39”S, 54²4'40"W. 08-IX-1910, Rodríguez 423 (SI). Depto. Oberá, Campo Viera. 23-X-1944, Ragonese et al. 2546 (SI). Depto. San Javier, Acaraguá. 14XII-1946, Bertoni 3175 (SI). Depto. San Pedro, Parque Provincial Cruce Caballero, picada en selva de Araucaria. $26^{\circ} 31^{\prime} \mathrm{S}, 5^{\circ} 59^{\prime} \mathrm{W} .510 \mathrm{~m}$ s. n. m. 20-I-2004, Biganzoli et al. 1285 (SI). BRASIL. Rio Grande do Sul. Boa Vista, Salvador do Sul. 150 m s. n. m. 13-IV-1974, Klein et al. 11101 (SI). Sarandí, 1967, Fragomeni 3 (SI).

Bauhinia affinis Vogel, Linnaea 10 (5): 594. 1836.

Iconografia. Fortunato (1996: Fig. 1).

Arbustos o arbolitos perennes, 4-7 m alt.; ramas teretes, levemente pilosas. Acúleos (1-) 2, dimorfos, alterno-opuestos, el mayor de 0,3-0,4 x 0,1-0,15 $\mathrm{cm}$, infraestipular, el menor de 1,25-1,5 $\mathrm{mm} \times 0,35-$ 0,5 mm, estipular. Estípula 0,5-2 x 0,25-0,5 mm, subuladas a deltoides-lanceoladas, tomentosas, tempranamente caedizas. Pecíolo 4-9 mm long., acanalado, piloso a subglabro; pulvínulos 1-2 mm 
Bol. Soc. Argent. Bot. 52 (3) 2017
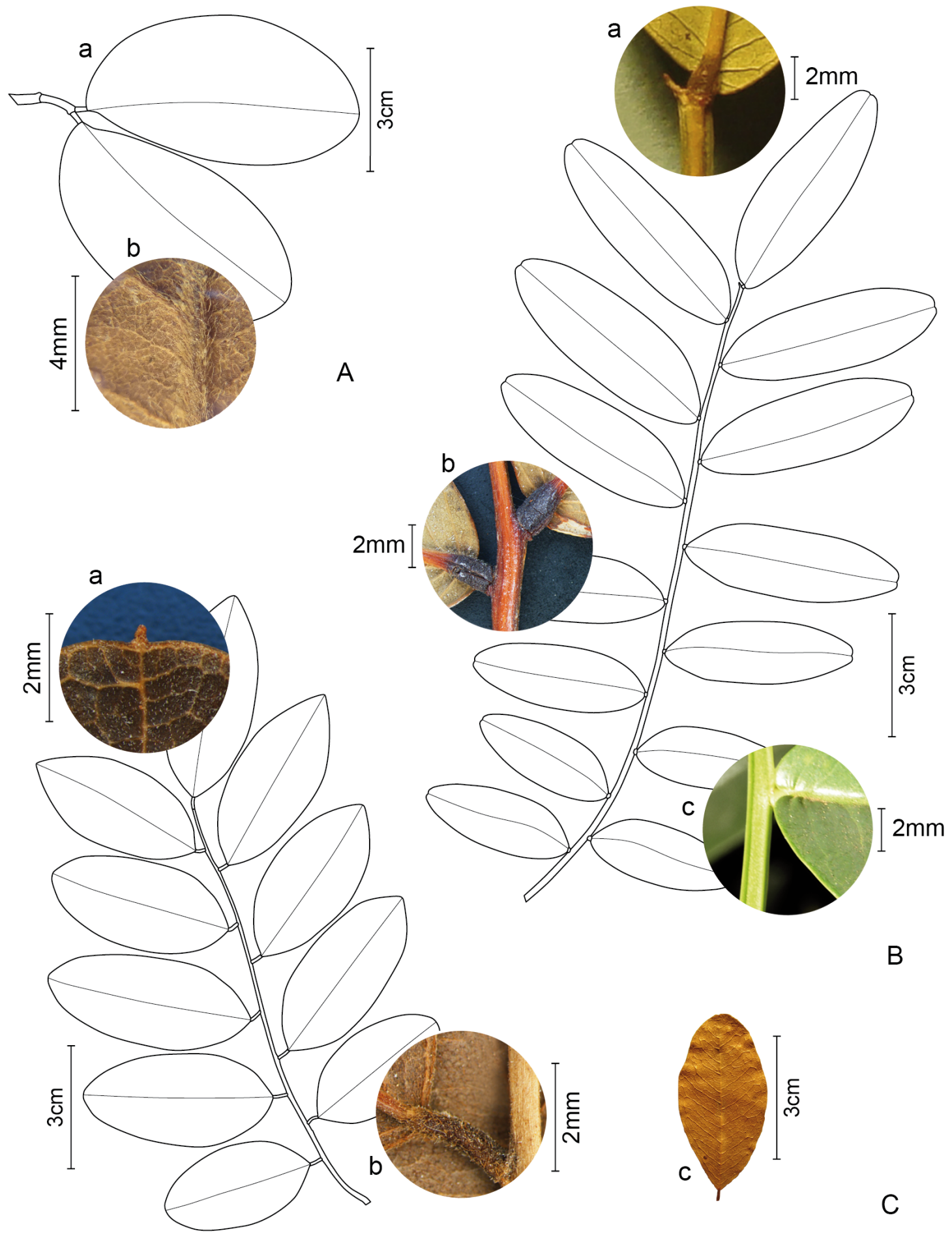

B

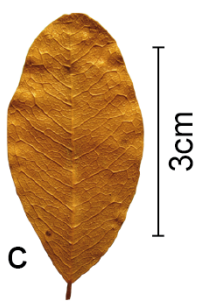

Fig. 1. Formas de las hojas en especies Caesalpinioideae de la Provincia de Misiones (Argentina). A. Hymenaea martiana. a. Hoja. b. Pubescencia en el envés. B. Pterogyne nitens. a. Extremo del raquis. b. Pulvínulos de los folíolos. c. Detalle del raquis. C. Apuleia leiocarpa. a. Ápice del folíolo. b. Peciólulo. c. Folíolo. A. de Jörgensen 3763 (SI). B. de Kostlin 99 (SI). C. de Bertoni 3175 (SI). 
long., pilosos. Hojas cartáceas a subcoriáceas, nervio marginal notorio en la cara abaxial; lóbulos de 2,6-5,5 x 1,2-2,3 cm, base cordada a obtusa, cara adaxial glabra, cara abaxial pubérula con pelos pluricelulares, levemente glandulosa.

Nombre vernáculo. Pata de vaca.

Distribución y hábitat. Crece en el SE de Brasil (Santa Catarina y Paraná), y en Argentina en los bañados de las nacientes del arroyo Pepirí Guazú (Misiones) en la región limítrofe con el Brasil dentro de la Prov. Biogeográfica Paranaense (Fortunato, 1996).

Observaciones. Florece de octubre a diciembre y fructifica desde noviembre (Fortunato, 1996).

Material examinado. ARGENTINA. Prov. Misiones. Depto. General Manuel Belgrano, Bernardo de Irigoyen, costa del Pepirí Guazú cerca de la Aduana. 26 $6^{\circ} 16^{\prime} \mathrm{S}, 53^{\circ} 36^{\prime} \mathrm{W}, 980 \mathrm{~m}$. s. m. 05-II-2003, Fortunato et al. 8041 (BAB, SI). Bernardo de Irigoyen, naciente del río Pepirí Guazú. $26^{\circ} 15^{\prime} \mathrm{S}, 53^{\circ} 38^{\prime} \mathrm{W}, 800$ m s. n. m. 19-XI1995, Guaglianone 2953 (SI). Depto. Iguazú, Parque Prov. Urugua-í, Ruta Prov. 19, $50 \mathrm{~km}$ de

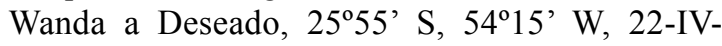
1997, Morrone et al. 2003 (SI).

Bauhinia forficata Link subsp. pruinosa (Vogel) Fortunato et Wunderlin, Darwiniana 27 (1-4): 550. 1986. Bauhinia pruinosa Vogel, Linnaea 13: 301. 1839.

Iconografía. Fortunato (1986: 551. fig. 6).

Árboles o arbolitos perennes, hasta $10 \mathrm{~m}$ alt. Acúleos 2 de 1,5-7 mm long. Hojas alternas, dísticas, cartáceas a subcoriáceas; estípulas de 0,5-5 x 0,5-1 mm, deltoide-lanceoladas, pilosas, caedizas. Pecíolo de 1-3 cm long., acanalado. Lóbulos de 4-11 x 1,5-5,5 cm, concoloros, obtusos, raros agudos, base cordada a redondeada; cara adaxial glabra, cara abaxial tomentosa a estrigosa, glandulosa, el indumento más bien localizado en la base de los nervios.

Nombres vernáculos. Falsa Caoba, Pata de cabra, Pezuña de vaca, Toro pó, Pata de Buey.
Distribución y hábitat. Se encuentra en el este de Paraguay, sur de Brasil, noroeste de Uruguay y en Argentina en las Prov. Biogeográficas Paranaense (Misiones, Corrientes), Espinal (Corrientes, Entre Ríos) y Chaqueña (Formosa, Chaco) (Fortunato, 1997). Es una especie heliófila de bordes de selva (Bernardi, 1984).

Observaciones. Florece de diciembre a febreromarzo y fructifica desde febrero a marzo-abril (Fortunato, 1986). Las alturas declaradas en las observaciones de los ejemplares analizados varían entre 2-4,5 m alt.

Material examinado. ARGENTINA. Prov. Misiones. Depto. General Manuel Belgrano, Ruta Nac. 14 de Bernardo de Irigoyen a Tobuna, $14 \mathrm{~km}$ del empalme con Prov. $17^{\circ} 26^{\prime} 23^{\prime}$ ' S, 53⒋ $48^{\prime}$ W, 750 m s. n. m. 1-III-1995, Zuloaga et al. 5126 (SI). Depto. Guaraní, Ruta 21 a $2 \mathrm{~km}$ de Ruta 14, hacia Moconá. $26^{\circ} 42^{\prime}$ S, $54^{\circ} 11^{\text {'W }}, 570$ m s. n. m., 13-XII1997, Múlgura de Romero et al. 1820 (SI); Fracrán, 15-II-1978, Cabrera et al. 29221 (SI). Depto. Iguazú: Ruta Nac. 101, Arroyo Santo Domingo. $25^{\circ} 40^{\prime}$ S, $54^{\circ} 15^{\prime}$ W. 5-03-1995, Zuloaga et al. 5276 (SI). Dpto. Libertador General San Martín, Valle Del Arroyo Cuñá Pirú, Ruta 7 hacia Aristóbulo Del Valle, Predio UNLP, cerca de la entrada al balneario. 19-VII-1998, Biganzoli et al. 98 (SI).

Bauhinia microstachya (Raddi) J. F. Macbr., Contr. Gray Herb. 59: 22. Schnelia microstachya Raddi, Mem. Soc. Ital. Modena 18: 412. 1820.

Iconografía. Fortunato (1986: 540, fig. 3).

Lianas o arbustos escandentes perennes; tallos adultos comprimidos, flexuosos a ondulados. Zarcillos 1 (2) intra-estipulares, simples, leñosos, en nudos de ramas apicales. Estípulas 0,5-1 x 0,25$0,5 \mathrm{~mm}$, triangulares a lanceoladas, tempranamente caedizas. Pecíolo 1-5 mm long. Hojas cartáceas a subcoriáceas; lóbulos 3-9 x 1,5-5 cm, agudos a obtusos.

Nombres vernáculos. Escalera de mono, Cipó escalera, Caí escalera.

Distribución y hábitat. Habita regiones tropicales y subtropicales de América Latina, concentrándose 
mayormente en Brasil desde el estado de Amazonas hasta Rio Grande do Sul. En Argentina crece en las selvas de la Prov. Biogeográfica Paranaense (Misiones, Corrientes) (Fortunato, 1997).

Observaciones. Florece de enero a marzo-abril y fructifica desde abril a junio (Fortunato, 1986).

Material examinado. ARGENTINA. Prov. Misiones. Depto. Eldorado, Selva costa del río Paraná. 7-XII-1943, Burkart 14531 (SI). Depto. Guaraní, Ruta Prov. 21, 30 km de Paraíso, caminando al W a $7 \mathrm{~km}$ de la ruta, 23-II-1999, Zuloaga et al. 6831 (SI). Depto. Tobuna, Santa Rosa, 15-II-1952, Capurro 1011 (SI).

Bauhinia uruguayensis Benth. In Martius, $F l$. Bras. 15 (2): 209. 1870.

Iconografia. Burkart (1969: Fig. 3-4); Fortunato (1986, Fig. 2).

Arbolitos o árboles perennes, 6-15 m alt.; ramas subflexuosas. Espinas 1-2 de 0,5-3 cm long., rectas, robustas, axilares a subaxilares, a veces ausentes en los nudos adultos, sin acúleos. Estípulas lanceoladas 1-2 mm long., tempranamente caedizas. Hojas cartáceas a subcoriáceas; lóbulos 2,5-9 x 1,5-5 $\mathrm{cm}$, agudos a levemente obtusos, cordados en la base, glabros, con la cara abaxial con el limbo y el pulvínulo basal levemente pubescente.

Nombre vernáculo. Pata de vaca.

Distribución y hábitat. Crece en el sur de Brasil (Estados de Paraná, Santa Catarina y Rio Grande do Sul), y en los cerrados pedregosos del Dpto. de Paraguarí en Paraguay. En Argentina crece en selvas ribereñas del río Uruguay en la Prov. Biogeográfica Paranaense de Corrientes y Misiones (Fortunato, 1997).

Observaciones. En esta especie pueden encontrarse hojas incisas (hojas bifolioladas) pero no es lo más frecuente. Florece de enero a marzo y fructifica desde octubre a noviembre (Fortunato, 1986).

Material examinado. ARGENTINA. Prov. Misiones. Depto. San Javier. Arroyo Pindaití, 13-
II-1947, Schwarz 4117 (LIL, SI). BRASIL. Paraná. Bocaiuva do Sul, Paranaí, 28-I-1958, Hatschbach 4436 (SI). Rio grande do Sul. Entre San Xavier y El atracador de La balsa, 31-I-1971, Ahum et al.1789 (SI). Santa Catarina. Munic. Dourado, Itapiranga, 250 m s. n. m., 3-III-1964, Klein 5232 (SI).

Copaifera langsdorffii Desf. var. langsdorffii Mém. Mus. Hist. Nat 7: 377. 1821.

Iconografía. Desfontaines (1821: pl. 14); Bentham in Martius (1870: tab. 63, fig. 1).

Árboles semi-caducifolios, (3) 6-12 m alt., inermes, resinosos, deciduos a semideciduos. Estípulas caedizas, escariosas. Pecíolos articulados. Hojas paripinnadas $5-10 \mathrm{~cm}$ long.; folíolos (2) 3-4 (6) pares, peciolulados, alternos o subopuestos, ovado-elípticos, de ápice retuso, base redondeada, 1,5-6 x 0,7-3 cm, coriáceos, reticulados, con puntuaciones glandulares translucidas en la lámina, nerviación prominente, margen foliar con nervio continuo, glándula sésil en el margen basal-externo de cada folíolo (Ver Figura 2).

Nombres vernáculos. Cupaí, Kupai, Cabreuva, Copaiba, Kopaiva, Timbó acá.

Distribución y hábitat. Desde Guyana, se extiende por Brasil, Paraguay y Bolivia. En Argentina se encuentra en la Prov. Biogeográfica Paranaense (Misiones) (Ulibarri, 1997b) de forma relictual en islas y borde de selvas sobre el río Iguazú (ver material de herbario).

Observaciones. Según el catálogo de Plantas Vasculares del Cono Sur (Zuloaga et al., 2008) existe únicamente la var. langsdorffii para Argentina. Las hojas nuevas rojizas y brillantes son muy características de la especie. Es una especie poco representada en Argentina (Ulibarri, 1997b), que conforma un endemismo, encontrándose circunscripta a la selva marginal en el curso superior del río Iguazú y cauces de agua aledaños (Vanni et al., 2003). Posee una corteza frecuentemente aromática. Del tronco de este árbol se obtiene el bálsamo de copaiba (Burkart, 1952). Florece de septiembre a febrero, y fructifica desde abril a septiembre (López et al., 1987). 

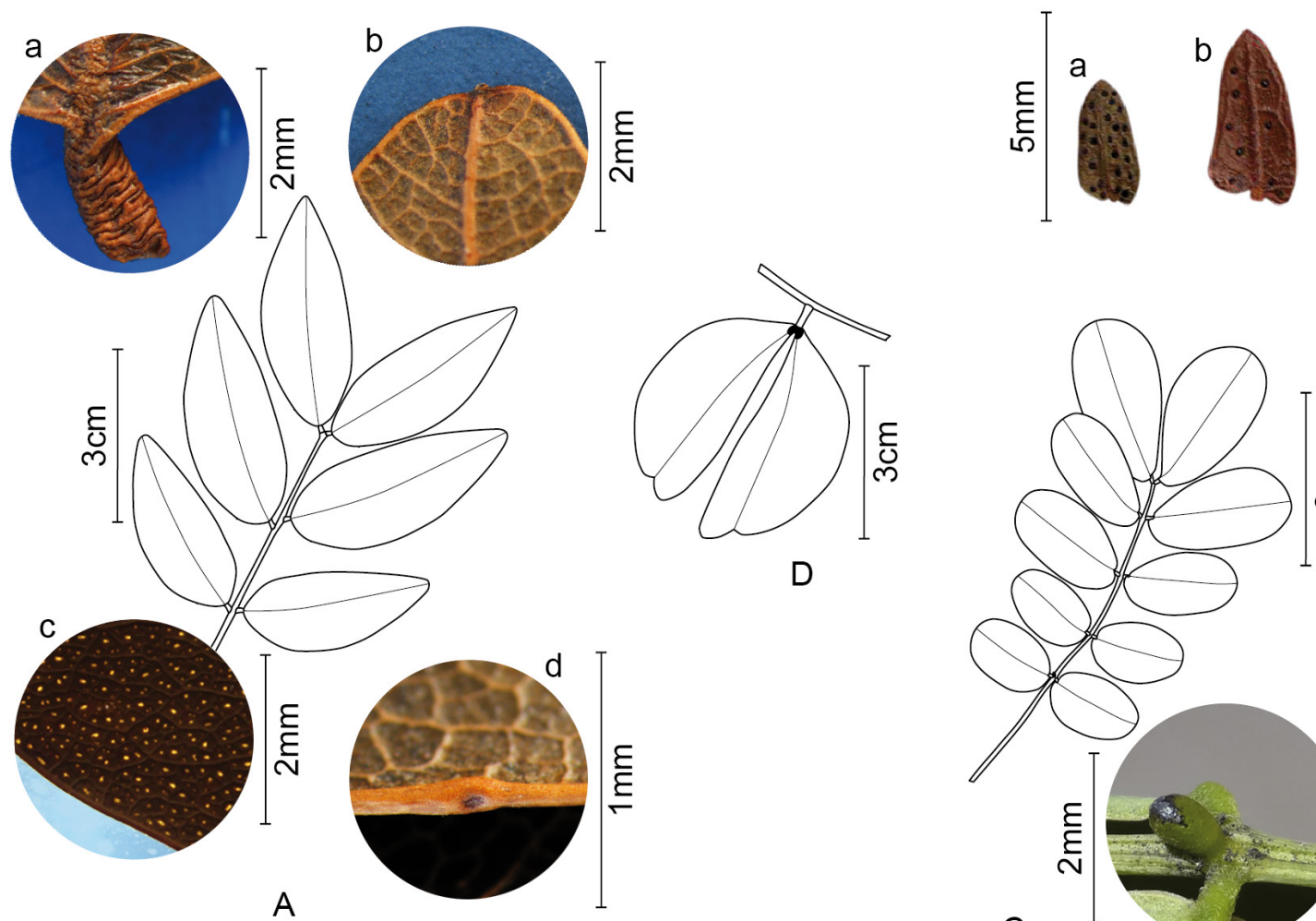

B

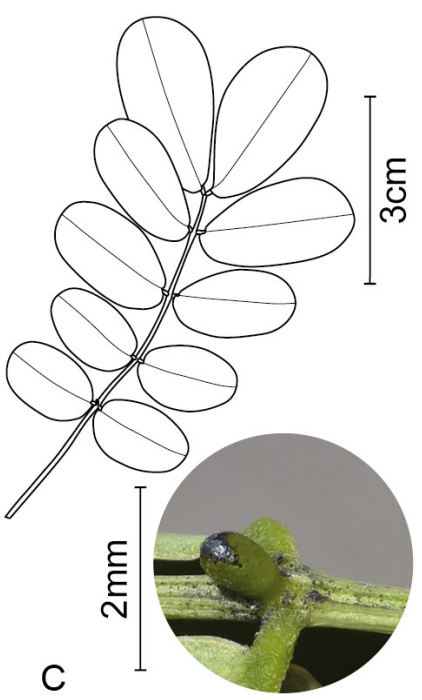

Fig. 2. Formas de las hojas en especies Caesalpinioideae de la Provincia de Misiones (Argentina). A. Copaifera langsdorffii var. langsdorffii. a. Peciólulo. b. ápice del folíolo. c. Puntos translúcidos de la lámina. d. Glándula en borde de la lámina. B. Pomaria rubicunda. a. Folíolo de la var. rubicunda. b. Folíolo de la var. haustalii. C. Senna pendula. a. Nectario extrafloral glanduloso sobre el raquis. D. Cynometra bauhiniifolia var. meridiana. A de Rodriguez 795 (SI), B de Zuloaga 6922 (SI) y Montes 558 (SI), C de Rodriguez 178 (SI), D de Lillo 313 (SI).

Material examinado. ARGENTINA. Prov. Misiones. Depto. Iguazú. Fragmento de selva entre los rápidos Cataratas del Iguazú, 5-V-1969, Eskuche 408 (SI). Salto Iguazú en islas, 19-IV-1913, Rodriguez 795 (SI). BRASIL. Paraná. Munic. Foz do Iguazú. Parque Nacional, cataratas do Iguaçu, $200 \mathrm{~m}$ s. n. m., 20-II-1963, Hatschbach 9750 (SI).

Cynometra bauhiniifolia Benth. var. meridiana Dwyer, Ann. Missouri Bot. Gard.: 338. 1958

Iconografia. Burkart (1952: 154. fig. $23 \mathrm{Cy})$.

Arbolitos o árboles perennes, 6-12 m alt. Filotaxis alterna espiralada. Estípulas mínimas filiformes. Pecíolo 2-6 mm long.; hojas bifolioladas disminuyendo en tamaño desde la base hacia el ápice, las basales de 4-1,5 cm long., las terminales $1 \mathrm{~cm}$ long., con 1 par de folíolos, asimétricamente obovados, de 1-4 x 0,5-2 cm, obtusos o emarginados, nervados, glabros, coriáceos (Ver Figura 2).

Nombres vernáculos. Manduvi-rá, Inga-pytá.

Distribución y hábitat. Endémica de Argentina, principalmente en la Prov. Biogeográfica Chaqueña (Chaco, Formosa) pero también en Misiones. Frecuente en lugares húmedos y a lo largo de ríos (Ulibarri, 1997b).

Observaciones. Según el Catálogo de Plantas Vasculares del Cono Sur (Zuloaga et al., 2008) existe 
sólo la var. meridiana para la prov. de Misiones. Los caracteres vegetativos fueron observados a nivel de especie. El margen de los folíolos enrollado y la cara adaxial lustrosa definen a esta variedad (Ulibarri, 1997b). Florece y fructifica desde octubre a enero.

Material examinado. ARGENTINA. Prov. Formosa. Río Paraguay, 11-XI-1909, Lillo 313 (SI). S. loc., I-1918, Jörgensen 2124 (SI). PARAGUAY. Central. Itá Enramada, Orillas Río Paraguay, X-1971, Schinini 4087 (SI). Presidente Hayes. Remansito, Chaco Paraguayo, barranca de Río Paraguay, 17-I-1948, Rojas 14046 (SI). San Pedro. Puerto Antequera, montes orilla Río Paraguay, XII1916, Rojas 2115 (SI).

Gleditsia amorphoides (Griseb.) Taub., Ber. Deutsch. Bot. Ges. 10 (10): 638. 1892. Garugandra amorphoides Griseb., Symb. fl. Argent.: 97. 1879.

Iconografía. Burkart (1987: 534, fig. 241). Martínez (1975: 480, fig. 10).

Árboles caducifolios 3-10 (20) m alt., espinas (cuando las tiene) caulinares ramificadas con distribución irregular, a menudo formando ramilletes, 20-25 cm long. Estípulas caducas. Ramas breves con hojas fasciculadas, pinnadas, 4-17 cm long., con 6-15 pares de folíolos. Ramas largas con hojas dispersas, pinnadas y bipinnadas, 2-4 pares, amplias. Folíolos elípticos 6-15 pares, alternos hasta opuestos, herbáceos, levemente discoloros, 1-4 x 0,41-7 cm, con margen crenado-dentado y base cuneado-asimétrica.

Nombres vernáculos. Espina Corona, Corona de Cristo, Espinillo amargo, Korondá, Nuatí kurusu guasu, Palo de corona, Yucará, Yvopé guazú, Acucaráfaveiro.

Distribución y hábitat. Crece en Bolivia, Paraguay y raramente en Brasil. En Argentina crece en la Prov. Biogeográfica Chaqueña (Chaco, Formosa, Jujuy, Salta); Paranaense (Misiones); Espinal (Corrientes, Entre Ríos, Santa Fe); Pampeana (Uruguay, extremo noroeste) (Ulibarri, 1997a). Según Marchiori (1997) en Brasil crece sobre todo en selvas en galería y barrancas de arroyos.

Observaciones. Florece de agosto-noviembre y fructifica desde enero-septiembre (López et al., 1987).
Burkart (1952) distingue por la ausencia/presencia de espinas dos variedades para la especie presentes en Misiones, var. anacantha y var. amorphoides, no obstante, habría que hacer nuevas colecciones y observaciones de campo para confirmar la validez de estas variedades, ya que en este trabajo no se observó esta variación. Los árboles son dioicos o poligamodioicos. Los ejemplares citados varían entre 10-20 m alt. y habitan interior de bosques.

Material examinado. ARGENTINA. Prov. Misiones. Depto. Cainguás. Mineral, 208 m s. n. m., 2-VI-1948, Montes 749 (SI). Depto. Candelaria.

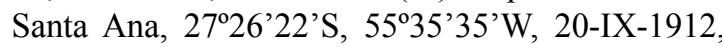
Rodríguez 608 (SI). Loreto, 218 m s. n. m. 21-VI1945, Montes 956 (SI). Dpto. Iguazú. Salto Iguazú, Sin fecha, Lillo 10554 (SI).

Hymenaea martiana Hayne, Arzneik. gebräuchl. Gewächses 11: pl. 15, 1830.

Iconografia. Hayne (1830: pl. 15). Lewis (2005: pág. 80). Lee \& Langenheim (1975: Fig.).

Árboles semi-caducifolios de $10 \quad(-30$ 40) $\mathrm{m}$ alt., inermes, resinosos. Ramas estriadas longitudinalmente. Filotaxis alterna espiralada. Estípulas lineares intrapeciolares caedizas dejando cicatriz con resina. Hojas 2-folioladas, folíolos oblongo-ovados, con ápice subobtuso, la parte basal externa redondeada de 5,5-7 x 2,5-4,5 cm, subcoriáceos a coriáceos, pubescentes en el envés, con puntuaciones glandulares en la lámina (ver Figura 1).

Nombre vernáculo. Yataihuá.

Distribución y hábitat. Habita en selvas poco húmedas hasta secas en el este de América del Sur, desde el sur de Ceará (Brasil) al norte de Argentina.

Observaciones. Florece en diciembre y fructifica enero-marzo (Queiroz, 2009). Se extrae el bálsamo del copal de su corteza (Burkart, 1952). Especie poco representada en herbario para la Provincia de Misiones.

Material examinado. ARGENTINA. Prov. Misiones. Depto. Leandro N. Alem. Leandro Alem, s. fecha, Barreiro s.n. (Ex Herb. Direc. Forestal Min. Agric. No. 1569, SI). Prov. Corrientes. Depto. 
Ituzaingó. Destacamento Prefectura Yahapé, 18-XII1997, Honfi 938 (MNES). PARAGUAY. Guairá. Villarrica, I-1930, Jörgensen 3763 (SI).

Peltophorum dubium (Spreng.) Taub., in Engler und Prantl, Nat. Pflanzenfam. 3 (3): 176. 1892. Caesalpinia dubia Spreng., Syst. Veg. 2: 343. 1825.

Iconografia. Bentham, in Martius (1870: t. 20. (sub nom. P. vogelianum); Burkart, in Troncoso \& Bacigalupo (1987: 529, f. 239).

Árboles caducifolios, hasta $35 \mathrm{~m}$ alt., copa amplia. Ramas lenticeladas. Estípulas caducas, lineares, pinnadas, 2-3 dientes subulados de cada lado o unilaterales. Hojas paribipinnadas, 12-30 cm long.; pecíolo y raquis pulverulentos; pinnas 7-21 pares; folíolos subsésiles, 6-30 pares con tricomas glandulares en cada inserción, elípticos-oblongos, opuestos, 5-14 x 2,5-5,5 mm, lustrosos en el haz, base asimétrico, margen revoluto, ápice apiculado, pinnatinervados, opacos en la cara abaxial (Ver Figura 3).

Nombres vernáculos. Yvyrá-pytá, Caña fistula, Árbol de Artigas.
Distribución y hábitat. Habita en la provincia Biogeográfica Paranaense, sur de Brasil, Paraguay, Noroeste de Uruguay, con algunas introducciones en la Prov. Biogeográfica Chaqueña y del Espinal en Argentina (Formosa, Chaco, Misiones, Corrientes, Santa Fe y Entre Ríos). Crece en partes altas de montes ribereños y en islas del río Uruguay (Ulibarri, 1997a). Especie heliófila y con características de pionera, de crecimiento rápido (Marchiori, 1997).

Observaciones. Florece de noviembre-mayo y fructifica desde abril-diciembre (López et al., 1987). Tronco cilíndrico generalmente ahuecado en los primeros metros, de fuste relativamente corto, de 60-120 cm diám. Corteza grisácea, con exfoliación irregular en pequeñas placas. Follaje verde-oscuro.

Material examinado. ARGENTINA. Prov. Misiones. Depto. Candelaria. Santa Ana, XII-1912, Rodriguez 670 (SI). Depto. Capital. Posadas, 10-IV1930, Rodriguez 168 (SI). Depto. Guaraní, camino a $13 \mathrm{~km}$ de San Vicente entre RN 14 y camping El Maynó, 9-I-2008, Kostlin 4 (SI). Depto. Iguazú, entre Puerto Aguirre e Iguazú. I-1907, Wolffhügel et al. 124 (SI).

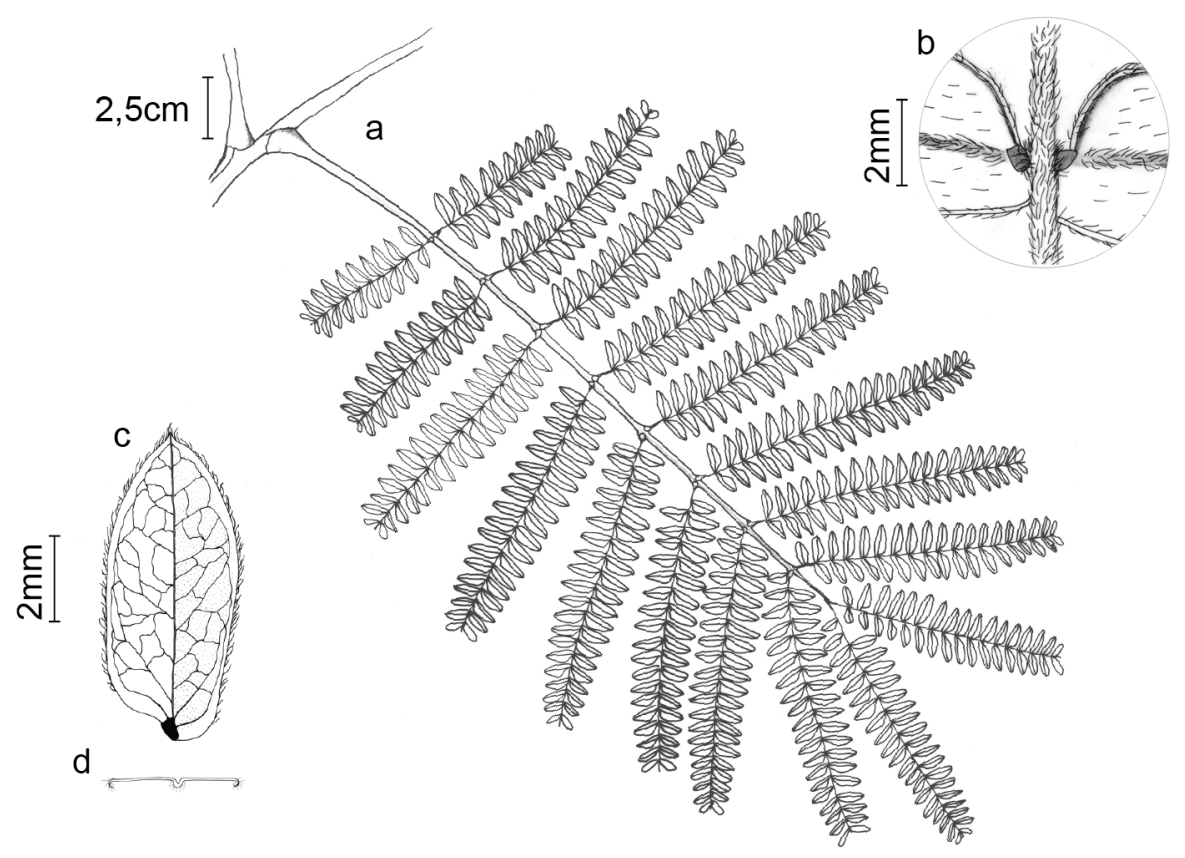

Fig. 3. Peltophorum dubium. a. Hoja. b. Inserción de folíolos en el raquis (envés). c. Folíolo. d. Corte transversal del folíolo. De Kostlin 4 (SI). 
Pomaria rubicunda (Vogel) B. B. Simpson \& G. P. Lewis var. hauthalii (Harms) B. B. Simpson \& G. P. Lewis. Caesalpinia hauthalii Harms, in Kuntze, Revs. gen. pl. 3, 2: 54. 1898.

Iconografía. Burkart (1936: 87. fig. 2).

Arbusto, 0,20-1 m alt., pubescencia breve, glándulas negras incrustadas laxamente en ramas y folíolos. Estípulas lineares persistentes. Hojas (2-) 3-8 (-11) pares de pinnas; folíolos (5-) 8-15 (-27) pares, $0,4-0,9 \times 0,15-0,3 \mathrm{~cm}$, deltoides-ovados a cordiformes, generalmente agudos; nervadura conspicua (ver Figura 2).

Distribución y hábitat. Crece en campos en forma aislada, en matorrales y márgenes de selvas. Distribución limitada a Paraguay, sudoeste del Brasil, y en Argentina solo se encuentra en la zona sur de Misiones (Ulibarri, 1997a).

Observaciones. Florece y fructifica de agosto a abril (Ulibarri, 1997a).

Material examinado. ARGENTINA. Prov. Misiones. Depto. Candelaria. Santa Ana, $27^{\circ} 23^{\prime}$ S, 553' 'W, 03-XII-1946, Schwarz 3534 (SI). Loreto, 218 m s. m., 13-II-1945, Montes 558 (SI).

Pomaria rubicunda (Vogel) B. B. Simpson \& G. P. Lewis var. rubicunda. Cladotrichium rubicundum Vogel, Linnaea 11: 401. 1837.

Iconografia. Bentham in Martius (1870: tab. 23, fig. 2); Burkart (1936: 87, fig. 2 B, b, b', lám. 5).

Arbustos, 0,50-2 (-3) m alt., glandulosos. Ramas rojizas. Estípulas lineares persistentes. Hojas 3-7 pares de pinnas; folíolos (4-) 8-16 pares, sésiles, opuestos (1,5-) 2-7 x 1-4 mm, subcoriáceos, glabros o laxamente pilosos, deltoide-cordiformes a ovado-elípticos, obtusos o subagudos, de base acorazonada a asimétrica (ver Figura 2).

Nombres vernáculos. Acacia roja, Ceibito, Ceibito de bañado.

Distribución y hábitat. Habita en campos graminosos, bajos y en el borde de selvas, entre los 140-800 m s. m. Crece en los departamentos de la zona sur de Misiones y Corriente (Ulibarri, 1997a).

Observaciones. Los ejemplares observados varían entre 0,40-2,5 m alt., con grueso xilopodio. Florece y fructifica de septiembre a abril (Ulibarri, 1997a).

Material examinado. ARGENTINA. Prov. Misiones. Depto. Apóstoles. Arroyo Chimiray, límite con Corrientes, $28^{\circ} 5^{\prime} 55^{\prime}$ 'S, $55^{\circ} 42^{\prime} 60^{\prime \prime} \mathrm{W}$, 14-XII-2007, Zuloaga et al. 9812 (SI). Depto. Candelaria. Entre arroyo San Juan y Candelaria-

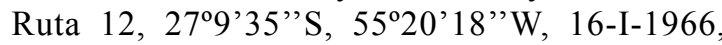
Krapovickas 12072 (SI). Camino hacia Ruta Prov. 12, a unos $500 \mathrm{~m}$ desde el Penal, Campo

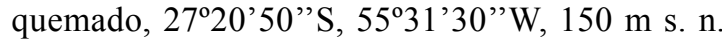
m., 22-IX-2000, Múlgura de Romero 2259 (SI). Ruta Prov. 204, de Candelaria a Profundidad, 3 $\mathrm{km}$ de Candelaria, $27^{\circ} 29^{\prime} \mathrm{S}, 55^{\circ} 44^{\prime} \mathrm{W}, 60 \mathrm{~m} \mathrm{~s}$. m., 26-II-1999, Zuloaga 6922 (SI). Depto. Capital.

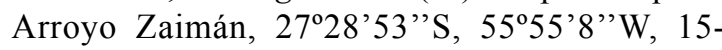
I-1972, Lirussi 1055 (SI). Depto. Concepción. Estancia de Elsa Prates sobre el río Uruguay, Isla de bosque en campo pastoreado, $28^{\circ} 5^{\prime} 28^{\prime}$ 'S, 5532'41' 'W, 160 m s. n. m., 28-I-2004, Biganzoli 1689 (SI). Depto. Leandro N. Alem. Ruta Cerro Azul - San José, a $100 \mathrm{~m}$ de Arroyo Liso, 27³6'9'"S, 55²3'18'W, 17-III-1968, Maruñak 35 (SI). Depto. San Ignacio. Teyú Cuaré, 9-III1946, Montes 1984 B (SI).

Pterogyne nitens Tul., Ann. Sci. Nat., sér. 2, 20: 140. 1843.

Iconografia. Bentham, in Martius (1870: tab. 64).

Árboles caducifolios, porte medio hasta $30 \mathrm{~m}$ alt. Filotaxis alterna, espiralada. Estípulas pequeñas tempranamente caducas, intrapeciolares. Hojas paripinnadas o pseudo-imparipinnadas; raquis acanalado, se prolonga después de los folíolos; folíolos (4-) 7-8 pares, generalmente alternos, anchamente elípticos, raro subobovados, ápice retuso, 3,5-6 x 1.5-2,5 cm, glabros, nervados, brillantes en el haz, subcoriáceos, sésiles, de margen entero, revoluto, base redondeada (Ver Figura 1). 
Nombres vernáculos. Viraró, Ibiraró, Guiraró, Amendoim.

Distribución y hábitat. Habita el sudoeste de Brasil, Bolivia, Paraguay. En Argentina en la Prov. Biogeográfica Chaqueña y Paranaense. Crece en valles, montes ribereños y selvas (Ulibarri, 1997a).

Observaciones. Florece de enero-marzo y fructifica desde marzo-noviembre (López et al., 1987).

Material examinado. ARGENTINA. Prov. Misiones. Depto. San Ignacio. Club de Pesca y Náutica San Ignacio, al lado de la Prefectura, 14-II2010, Kostlin 99 (SI). Prov. Corrientes. Depto. San Cosme. Paso de la Patria, Costa Toledo, 55 m s. n. m., V-1945, Meyer 8859 (SI). BRASIL. Paraná. Cândido Rondon. Porto Mendes, 24-IV-1968, Hatschbach 19146 (SI).

Senna corymbosa (Lam.) H.S. Irwin \& Barneby, Mem. New York Bot. Gard. 35(1): 397. 1982. Cassia corymbosa Lam., Encycl. 1(2): 644. 1785.

\section{Iconografia. Burkart (1987: 518, fig. 233).}

Arbustos o arbolitos erectos, 0,5-3 m alt. Ramas glabras. Estípulas lineares, 3-6 mm long. Hojas, 6-14 cm long.; pecíolo 1,9-4,2 cm long.; nectarios extraflorales glandulosos pedicelados lanceolados o estipitadas presentes entre el primer par de folíolos, 2-3(-4) pares, largamente ovados, glabros, ápice agudo a subagudo, mucronado o no, base oblicua u obtusa, folíolos distales mayores, angostamente elípticos, de base asimétrica.

Nombres vernáculos. Rama negra, Caña fístula, Sena, Sena-do-mato, Sen del campo, Fe do goso.

Distribución y hábitat. Habita Brasil austral, Uruguay y Argentina (Tucumán, Misiones, Córdoba, Corrientes, Entre Ríos, y el noreste de Buenos Aires). Crece en campos húmedos o arenosos, en vegetación secundaria y en bordes de la selva (Schütz Rodrigues et al. 2005).

Observaciones. Florece de enero a marzo y fructifica de marzo a junio (Ulibarri et al., 2002). Según Irwin \& Barneby (1982) los nectarios extraflorales pueden aparecer también entre el segundo o tercer par de folíolos. Esto no se ha podido observar en el material analizado. Especie poco representada en colecciones de Misiones.

Material examinado. ARGENTINA. Prov. Misiones. Depto. Apóstoles. Arroyo Chimiray, 29-XI-1943, Burkart 14298 (SI). Prov. Corrientes. Depto. Monte Caseros. Mocoretá, Ruta 14, 25-VI1952, Nicora 6244 (SI).

Senna oblongifolia (Vogel) H.S. Irwin \& Barneby, Mem. New York Bot. Gard. 35 (1): 374. 1982. Cassia oblongifolia Vogel, Syn. Gen. Cass. 23. 1837.

Iconografia. Izaguirre \& Beyhaut (2003: 72, Fig. 14 B).

Arbustos o arbolitos, erectos, 2-7 (-10) m alt., ramas glabras. Estípulas linear-lanceoladas, 4-13 mm long. Hojas, 6-23,5 cm long.; pecíolo 1,7-6,5 cm long., glándulas estipitadas, presentes en la zona media, folíolos (3-) 4-9 (-10) pares, largamente subobovados a anchamente elípticos, base oblicua, cuneada u obtusa, los distales 2-6,6 $\times 0,8-1,8 \mathrm{~cm}$, cara abaxial a veces con escasa pilosidad hacia la base.

Distribución y hábitat. Habita en Uruguay, sur y sureste de Brasil. En Argentina crece en el extremo noreste de la provincia de Misiones. Crece en campos arbustivos, vegetación secundaria, borde e interior de las selvas con Araucaria angustifolia (Bertol.) Kuntze (Schütz Rodrigues et al. 2005).

Observaciones. Suele confundirse con S. pendula. Según Irwin \& Barneby (1982) los nectarios extraflorales glandulosos de $S$. oblongifolia se encuentran siempre en la parte media del pecíolo y, algunas veces, también entre los folíolos de los pares proximales. Esto último no se ha observado en el material estudiado. Los ejemplares examinados variaron entre 2-7 m alt., creciendo en margen de selva secundaria, asociados a borde de caminos. Florece de noviembre a marzo $\mathrm{y}$ fructifica desde febrero a mayo.

Material examinado. ARGENTINA. Prov. Misiones. Depto. Gral. Manuel Belgrano. Cerro El 
Tigre, Ruta Nacional 14, 11-XI-1973, Boelcke et al. 5468 (SI). Ruta Nac. 14, 14 km de Bernardo de Irigoyen, camino a Tobuna $26^{\circ} 19^{\prime} \mathrm{S}, 53^{\circ} 44^{\prime} \mathrm{W}, 16$ II-1996, Morrone et al.860 (SI). De Piñalito a Dos Hermanas, Ruta 14 a $12 \mathrm{~km}$ de La Ruta a B. de

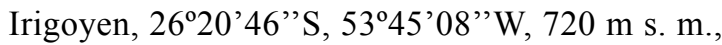
17-XII-2007, Zuloaga et al. 9932 (SI). Depto. San Pedro. Bernardo de Irigoyen, 17-X-1975, Zardini et al. 917 (SI). San Pedro, 8-XI-1886, Niederlin 752 (SI). Ruta 14, desde Bernardo de Irigoyen hacia Tobuna, $26^{\circ} 20^{\prime} \mathrm{S}, 53^{\circ} 44^{\prime} \mathrm{W}, 600 \mathrm{~m}$ s. m., 17-XII-1997, Múlgura de Romero et al. 1936 (SI).

Senna pendula (Willd.) H.S. Irwin \& Barneby, Mem. New York Bot. Gard. 35 (1): 378. 1982. Cassia pendula Willd., Enum. pl. 1. 440. 1809.

Iconografía. Burkart (1987: 517, fig. 232).

Arbustos o arbolitos, erectos, 2-3 m alt., ramas glabras o pubérulas. Estípulas linear-lanceoladas, 2-11 mm long. Hojas, 4,5-13 cm long.; pecíolo 1,3-4,3 cm long.; glándulas ovoides, globosas o estipitadas presentes entre los folíolos del primer par; (3-) 4-6 pares folíolos, anchamente elípticos, con ápice obtuso o retuso, emarginado, base oblicua, folíolo distal 2-4,6 × 1-2,2 cm (Ver Figura 2).

Nombres vernáculos. Canudo-de-pito, Yerba de burro.

Distribución y hábitat. Amplia distribución desde Estados Unidos hasta Argentina. Crece en vegetación secundaria de diversos ambientes desde zonas inundables a ambientes xerófilos entre otros.

Observaciones. Se ha observado a nivel de especie, aunque existen dos variedades para la misma, citadas para la provincia de Misiones: S. pendula (Willd.) H. S. Irwin \& Barneby var. paludicola $\mathrm{H}$. S. Irwin \& Barneby y $S$. pendula (Willd.) H. S. Irwin \& Barneby var. missionum H. S. Irwin \& Barneby. No se han observado nectarios extraflorales fuera del primer par de folíolos como se comenta en Irwin \& Barney (1982). Los ejemplares examinados son arbustos o arbolitos de 2,5-5 $\mathrm{m}$ alt. Florece y fructifica en marzo.
Material examinado. ARGENTINA. Prov. Misiones. Depto. Candelaria. Santa Ana, camino, VII-1927, Burkart 1385 (SI). Depto. Capital. Posadas, 19-IV-1920, Rodriguez 178 (SI). Depto. Eldorado. Eldorado, Escuela Agrotécnica, $26^{\circ} 17^{\prime} 58^{\prime} \mathrm{S}$, 54²5'40"W, 5-I1972, Quarín 328 (SI). Depto. Oberá. Entre Campo Viera y Campo Grande, s. fecha, Zuloaga et al.1989 (SI).

\section{Discusión y Conclusiones}

Los caracteres vegetativos estudiados en este trabajo permiten la identificación de todos los taxones arbustivos-arbóreos y lianas de la subfamilia Caesalpinioideae nativos a nivel de género, especie y variedad, a escala geográfica de la provincia de Misiones (Argentina). En los casos de Pomaria rubicunda, Copaifera langsdorffii y Cynometra bauhiniifolia, los caracteres vegetativos foliares son indispensables para separar variedades como ya se había registrado en Ulibarri (1997a, 1997b) y Queiroz (2009) respectivamente.

Dentro de la diversidad morfológica de los caracteres vegetativos observados, los cuales son invariantes a nivel de especie dentro la subfamilia estudiada, se destacan: raquis o pecíolos surcados (Pterogyne nitens, Bauhinia spp.); glándulas translúcidas en la lámina (C. langsdorffii var. langsdorffii, Hymenaea martiana, Peltophorum dubium), borde revoluto de la lámina (C. bauhiniifolia var. meridiana, P. dubium, P. nitens), nectarios extraflorales o glándulas (Senna spp., C. langsdorffii var. langsdorffii), peciólulos corrugados (C. bauhiniifolia var. meridiana, $C$. langsdorffii var. langsdorffi, Hymenaea martiana, P. nitens), folíolos con nervio marginal continuo $(H$. martiana, C. langsdorffii var. langsdorffii), y cara adaxial lustrosa (H. martiana, C. langsdorffii var. langsdorffii, $P$. nitens). Es interesante destacar que la glándula marginal de los folíolos de $C$. langsdorffii var. langsdorffii es poco citada en la bibliografía, coincidiendo con la mención de Martins (2009). Cabe subrayar que ante la escasez de colecciones representativas de las especies C. bauhiniifolia var. meridiana e $H$. martiana, para la provincia de Misiones, se deberían realizar más recolecciones botánicas en esta región.

La identificación viable y certera de un taxón en base a caracteres vegetativos depende por un lado de la escala geográfica y la categoría taxonómica a 
analizar, así como de la buena descripción de la flora de la región en cuestión y del estado taxonómico del grupo a abarcar (Rejmanek \& Brewer, 2001). Cuando se trabaja en una escala geográfica de gran amplitud, como la pantropical, es casi imposible identificar un taxón sin flores y frutos a nivel de especie (Keller, 1994). Sin embargo, al identificar taxones en un área geográfica acotada, la consideración de caracteres vegetativos foliares resulta de gran utilidad (Rejmanek \& Brewer, 2001; Mantovani et al., 1985).

A partir del presente trabajo se destaca la necesidad de profundizar las investigaciones focalizando en la descripción de caracteres vegetativos con mayor detalle, ya que los mismos no siempre son mencionados y descriptos con la certeza suficientes (Weberling, 2006). Esto podría deberse a que no existe una visión global a la hora de describir el taxón ya que, dependiendo de la disciplina (e. g. ecología forestal, botánica sistemática), se describe al mismo en forma parcial y fragmentada.

Es fundamental continuar con las recolecciones y observaciones a campo, así como las revisiones de material herbario para mejorar los sistemas de identificación de las plantas, sobre todo en ecosistemas con gran biodiversidad y variabilidad fenológica como son los neotropicales. Esto puede lograrse a partir de realizar descripciones ordenadas mediante protocolos estandarizados, desde caracteres macroscópicos hasta los microscópicos y desde los caracteres vegetativos a los reproductivos, detallando la fenología foliar y floral, seleccionando una relación adecuada entre la escala geográfica a abarcar y la categoría taxonómica a identificar.

\section{Agradecimientos}

A Emilio A. Ulibarri quien me instruyó en el mundo de las leguminosas, algo fundamental para que este manuscrito se lleve a cabo. A Fernando Zuloaga, Manuel Belgrano, Cecilia Ezcurra, Cristian Torres y Eric Nicolini por leer este manuscrito y hacer grandes aportes y sugerencias, así como a los revisores anónimos. Al personal del herbario del Instituto Darwinion (SI), por facilitar el acceso al material de estudio. A Cristian Zanotti y Viviana Winiel por sus contribuciones en cuanto a la fotografía y digitalización de ilustraciones. Finalmente, a todo el personal del Instituto de Botánica Darwinion, por su acompañamiento y asesoramiento en mi paso por el IBODA.

\section{Bibliografía}

ASH, A. W., B. ELLIS, L. J. HICKEY, K. R. JOHNSON \& P. WILF. 1999. Manual of leaf architecture. Morphological description and categorization of dicotyledonous and net-veined monocotyledonous angiosperms. Washington DC: Smithsonian Institution.

BENTHAM, G. 1859-1876. Leguminosae. In: MARTIUS, C.F.P (ed.), Flora Brasiliensis 15, Part 1, pag. 1-332; Vol 15, Part 2, pag. 1-504 tab. 1-138.

BERNARDI, L. 1984. Contribución a la Dendrología paraguaya 1. Leguminosas. Boissiera 35: 120-341.

BOHREN, A., L. GRANCE, M. GARTLAND, D. MIRANDA, H. KELLER \& C. DUMMEL. 2003. Clave de reconocimiento de especies forestales de Misiones, argentina, por medio de la corteza. Yvyraretá 12: 26-40.

BRAZ, M. D., V. M. L. P. MOURA \& M. M. T. da ROSA. 2004. Chave de identificação para as espécies de Dicotiledôneas arbóreas da Reserva Biológica do Tinguá, RJ, com base em caracteres vegetativos. Acta bot. bras. 18: 225-240.

BURKART, A. 1936. Las especies argentinas y uruguayas del género Caesalpinia. Revista Argent. Agron. 3: 67-112.

BURKART, A. 1952. Las Leguminosas argentinas, silvestres y cultivadas. $2^{\mathrm{a}}$. ed. Acme, Buenos Aires.

BURKART, A. 1987. Leguminosas. En: TRONCOSO, N. S. \& N. BACIGALUPO (eds.). Flora Ilustr. Entre Ríos (Argentina). Colecc. Ci. Inst. Nac. Tecnol. Agropecu. 6: 510-518.

CABRERA, A. L. 1976. Regiones Fitogeográficas Argentinas. En: KUGLER, W. F. (ed.). Encicl. Argent. Agric. Jard. 1: 1-85.

CABRERA, A. L. \& A. WILLINK. 1980. Biogeografia de América Latina. Monografia $\mathrm{N}^{\mathrm{a}} 13$, Serie de Biología, Secretaría Gral. de la OEA, Washington.

COWAN, R. S. 1981. Caesalpinioideae. In: POLHILL, R. M. \& P. H. RAVEN. (eds.). Advances in Legume Systematics 2: 57-64. Kew Royal Bot. Gar.

DESFONTAINE, M. 1821. Observations sur le genre Copaifera; description de deux nouvelles espèces qui lui appartiennent. Mém. Mus. Hist. Nat. 7: 375-378.

DI BITETTI, M. S., G. PLACCI \& L. A. DIETZ. 2003. Una visión de biodiversidad para el Bosque Atlántico del Alto Paraná: diseño de un paisaje de conservación de la biodiversidad y prioridades para las acciones de conservación. Washington D.C.: World Wildlife Fund.

FONT QUER, P. 1985. Diccionario de Botánica. Editora Labor, Barcelona.

FORTUNATO, R. H. 1986. Revisión del género Bauhinia (Cercideae, Caesalpinioideae, Fabaceae) para la Argentina. Darwiniana 27: 527-557. 
FORTUNATO, R. H. 1996. Bauhinia affinis (Fabaceae) una nueva cita para la flora argentina. Darwiniana 34: 405-409.

FORTUNATO, R. H. 1997. Fabaceae (2) Tribu 3 Cercideae. In HUNZIKER, A. T. (ed.) Fl. Fanerog. Argent. 33: 4-9.

GARCÍA MURILLO, P. 1991. Identificación de las especies ibéricas y baleáricas del género Potamogeton L. en estado vegetativo. Limnetica 7: 71-82.

GENTRY, A. H. 1996. A Field Guide to the Families and Genera of Woody Plants of Northwest South America (Columbia, Ecuador, Perú). Washington D.C.: Conservation International.

GIRAUDO, A. R \& H. POVEDANO. 2004. Avifauna de la región biogeográfica Paranaense o Atlántica Interior de Argentina: biodiversidad, estado del conocimiento y conservación. Insugeo, Miscelánea, 12: 331-348.

IRWIN, H. S. 1981. Preface. In: POLHILL, R. M. \& P. H. RAVEN (eds.). Advances in legume systematics, part 1, pp.vii-xi. Royal Bot. Gar., Kew.

IRWIN, H.S. \& R. C. BARNEBY. 1982. The American Cassiinae-A Sypnoptical Revison of Leguminosae tribe Cassieae subtribe Cassiinae in the New World. Mem. New York Bot. Gard. 35: 1-918.

IZAGUIRRE, P. \& R. BEYHAUT. 2003. Las Leguminosas en Uruguay y regiones afines. Parte 2: Caesalpinioideae. Parte 3: Mimosoideae. Ed. Hemisferio Sur, Buenos Aires.

HARGREAVES, P. 2006. Vegetative morphology for species identification of tropical trees: family distribution. Cerne 12: 1-7.

HICKEY, L. J. 1974. Clasificación de la arquitectura de las hojas de Dicotiledóneas. Bol. Soc. Argent. Bot. 16: $1-26$.

HICKEY, L. J. \& J. A. WOLFE. 1975. The bases of angiosperm phylogeny: vegetative morphology. Ann. Missouri Bot. Gard. 62: 538-589.

KELLER, R. 1994. Neglected vegetative characters in field identification at the supraspecific level in woody plants: phyllotaxy, serial buds, syllepsis and architecture. Bot. J. Linn. Soc. 116: 33-51.

KELLER, R. 1996a. Identification of tropical woody plants in the absence of flowers. A field guide. Basel. Birkhauser. Verlag.

KELLER, R. 1996b. Identificación de las tribus de leguminosas leñosas en América tropical mediante el uso de caracteres vegetativos: propuesta de una clave de campo. Acta Bot. Venez. 19: 1-24.

LEWIS, G. P., B. SCHRIRE, B. MACKINDER \& M. LOCK. 2005. Legumes of The World. 1st. ed. Royal Bot. Gard, Kew.

LÓPEZ, J.A, E. LITTLE, G. RITZ, J. ROMBOLD \& W. HAHN. 1987. Árboles comunes del Paraguay: Ñande yvyra mata kuera. Paraguay, Cuerpo de Paz.
LPWG. 2017. A new subfamily classification of the Leguminosae based on a taxonomically comprehensive phylogeny. Taxon 66: 44-77.

MANTOVANI, W., H. F. DE LEITÃO FILHO \& F. R. MARTINS. 1985. Chave baseada em caracteres vegetativos para a identificação de espécies lenhosas do cerrado da Reserva Biológica de Moji Guaçu, Estado de São Paulo. Hoehnea 12: 35-56.

MARCHIORI, J. N. C. 1997. Dendrologia das Angiospermas: Leguminosas. Santa Maria. Ed. Universidade Federal de Santa Maria.

MARINO, G. D., M. V. MAS \& M. J. ORLANDONI. 2008. Morfología y reconocimiento de las principales especies leñosas nativas de la provincia de Santa Fe, Argentina, en el estado de plántula. Bol. Soc. Argent. Bot. 43: 67-81.

MARTÍNEZ, S. 1975. Estudio morfológico de las yemas axilares de algunas Leguminosas leñosas de la flora argentina. Darwiniana 19: 458-489.

MARTINS, M. V. 2009. Leguminosas arbustivas e arbóreas de fragmentos florestais remanescentes no noroeste paulista, Brasil. (Dissertação de mestrado). Universidade Estadual Paulista, Instituto de Biociências de Botucatu. Pp 1-161. [online]. Disponible en: https://repositorio.unesp.br/bitstream/ handle/11449/88121/martins_mv_me_botib. pdf? sequence $=1 \&$ isAllowed $=y$. [Acceso: 15 Marzo 2016].

MIRANDA, D. E., A. V. BOHREN, H. KELLER, L. A. GRANCE \& H. M. GARTLAND. 2000. Clave de reconocimiento de especies leñosas de Rutaceae presentes en la Selva paranaense (Argentina), mediante el uso de caracteres dendrológicos. Quebracho 8: 47-55.

NEWSTROM, L. E., G. W. FRANKIE \& H. G. BAKER. 1994. A New Classification for Plant Phenology Based on Flowering Patterns in Lowland Tropical Rain Forest Trees at La Selva, Costa Rica. Biotropica 26: 141-59.

PEREIRA, T. S., M. L. M. N. COSTA, L. F. D. MORAES \& C. LUCHIARI. 2008. Fenologia de espécies arbóreas em Floresta Atlântica da Reserva Biológica de Poço das Antas, Rio de Janeiro, Brasil. Iheringia, Sér. Bot 63: 329-339.

PUNTIERI, J. \& J. CHIAPELLA. 2011. Plántulas de la Patagonia: Guía breve de identificación. Ed. Caleuche.

QUEIROZ, L. P. 2009. Leguminosas da Caatinga. Feria de Santana: Universidade Estadual de Feira de Santana.

REJMANEK, M. \& S. W. BREWER. 2001. Vegetative Identification of tropical woody plants: State of the art and annotated bibliography. Biotropica 33: 214-228.

RIBEIRO, J. E. L. S., M. J. G. HOPKINS, A. VICENTINI, C. A. SOTHERS, M. A. S. COSTA, J. M. BRITO, M. A. D. SOUZA, L. H. MARTINS, L. G. LOHMANN, 
P. A. ASSUNÇÃO, E. C. PEREIRA, C. F. SILVA, MESQUITA M. R. \& L. C. PROCÓPIO. 1999. Flora da Reserva Ducke. Guia de identificação das plantas vasculares de uma floresta de terra firme na Amazônia Central. INPA-DFID, Manaus.

SCHÜTZ RODRIGUES, R., A. SILVA FLORES, S. T. SFOGGIA MIOTTO \& L. RIOS DE MOURA BAPTISTA. 2005. O gênero Senna (Leguminosae, Caesalpinioideae) no Rio Grande do Sul, Brasil. Acta Bot. Bras. 19: 1-16.

SILVA, M. F., G. H. GOLDMAN, F. M. MAGALHÃES \& F. W. MOREIRA. 1988. Germinação natural de 10 espécies arbóreas da Amazônia - I. Acta Amaz. 18: 9-26.

SIMPSON, B. B. \& G. P. LEWIS. 2003. New combinations in Pomaria (Caesalpinioideae) Kew Bull. 58: 175184.

SOBRAL, M., J.A. JARENKOW, P. BRACK, B. IRGANG, J. LAROCCA \& R. SCHÜTZ RODRIGUES. 2006. Flora Arbórea e Arborescente do Rio Grande do Sul. Brasil. São Carlos (SP). Ed. Rima: Novo Ambiente.

SOUSA, FILIPE DE PORTUGAL S. T., G. P. LEWIS \& J. A. HAWKINS. 2010. A revision of the South American genus Apuleia Martius (Leguminosae, Cassieae). Kew Bull. 65: 225-232.

ULIBARRI, E. A. 1996. Sinopsis de Caesalpinia y Hoffmannseggia (Leguminosae-Caesalpinioideae) de Sudamérica. Darwiniana 34: 299-348.

ULIBARRI, E. A. 1997a. Fabaceae (1) Caesalpinioideae, Tribu 1 Caesalpinieae. In: HUNZIKER, A. T. (ed.) Fl. Fanerog. Argent. 32: 3-26.

ULIBARRI, E. A. 1997b. Fabaceae (2) Tribu 4 Detarieae. In: HUNZIKER, A. T. (ed.) Fl. Fanerog. Argent. 33: 10-12.

ULIBARRI, E. A. 1997c. Fabaceae (8) Tribu 2 Cassieae. In: HUNZIKER, A. T. (ed.) Fl. Fanerog. Argent. 51: $3-4$.
UlibARRI, E. A., E. V. GÓMEZ-SOSA, A. M. CIALDELLA, R. H. FORTUNATO \& D. BAZZANO. 2002. Leguminosas, nativas y exóticas. In: HURRELL, J. H. Y LAHITTE, H. B. (eds.). Biota Rioplatense. 7. 1a. ed. 320 pp. Bs. As., Edit. L. O. L. A. (Literature of Latin America).

ULIBARRI, E. A. 2008. Los géneros de Caesalpinioideae (Leguminosae) presentes en Sudamérica. Darwiniana 46: 69-163.

URBANETZ, C., TAMASHIRO, J. Y. \& L. S. KINOSHITA. 2010. Chave de identificação de espécies lenhosas de um trecho de Floresta Ombrófila Densa Atlântica, no Sudeste do Brasil, baseada em caracteres vegetativos. Biota Neotrop. 10: 349-398.

VANNI, R. O., LÓPEZ, G. \& C. M. DÁVALOS. 2003. Inventario florístico del Parque Nacional Iguazú. Univ. Nac. del Nordeste. Comunicaciones Científicas y Tecnológicas. [online]. Disponible en: http:// www.unne.edu.ar/unnevieja/Web/cyt/cyt/2003/ comunicaciones/06-Biologicas/B-024.pdf. [Acceso: 15 Marzo 2017].

WEBERLING, F. 2006. Las estípulas como caracteres sistemáticos confiables. Bol. Soc. Argent. Bot. 41: 127-150.

ZULOAGA, O. F., O. MORRONE, \& M. J. BELGRANO. 2008. Catálogo de las plantas vasculares del Cono Sur (Argentina, sur de Brasil, Chile, Paraguay y Uruguay). Monogr. Syst. Bot Missouri Bot. Gard. 107.

ZULOAGA, F. O., O. MORRONE \& D. RODRIGUEZ. 1999. Análisis de la biodiversidad en plantas vasculares de la Argentina. Kurtziana 27: 17-167.

Recibido el 24 de noviembre de 2016, aceptado el 22 de marzo de 2017. 
